Article

\title{
Thermal Analysis of Busbars from a High Current Power Supply System
}

\author{
Adrian Plesca \\ Gheorghe Asachi Technical University of Iasi, Faculty of Electrical Engineering, Blvd. Dimitrie Mangeron, 21-23, \\ 700050 Iasi, Romania; aplesca@tuiasi.ro; Tel.: +40-232-278-683
}

Received: 8 May 2019; Accepted: 13 June 2019; Published: 14 June 2019

\begin{abstract}
Copper busbar technology is widely used with the aim to achieve electrical connections with power distribution systems because of their flexibility and compactness. The thermal analysis takes into account the heat conduction and convection of a copper busbar system used to supply a test bench with high currents in order to check the electro-thermal behaviour of power circuit breakers during overload and short circuit conditions. This paper proposes a mathematical model for busbars used within a high current power supply. The obtained thermal model can be used to analyse the thermal behaviour of busbars in steady-state conditions at different values of the electric current, cross-section and length of the busbar. Also, the mathematical model allows to calculate the temperature distribution along the busbar at different values of the contact resistances at junction points with other conductors. There is a good correlation between calculated, simulated and experimental results.
\end{abstract}

Keywords: Busbar; Temperature distribution; Mathematical model; Thermal modelling and simulation

\section{Introduction}

The power distribution based on copper busbar systems are used on large scale and have been accepted more and more due to their flexibility, safety and ability to reduce overall design and integration costs in industrial systems. Moreover, the globalization has prompted industrial control engineers to choose design techniques, electrical components, and industrial integration methods worldwide, based on increasingly complex busbar systems [1].

Power distribution systems which are using copper busbars have an innovative quality that traditional distribution methods based on cables can not offer. Thus, the new techniques with copper busbars provide the most efficient placements and the simplification of the bill of materials for the control panels. Actually, a busbar system replaces two important elements placed into a typical control panel: power distribution block and the connection cables. With the removal of the power distribution block and the connection wires, the designers can decrease the overall dimensions of the control panel $[1,2]$. In addition to design cost savings, a lower overall industrial control panel implies a lower price for the entire electrical system.

Using traditional techniques, the power distribution is achieved through the connection of the main circuit breaker to a power distribution block with large dimensions parallel cables. In turn, the power distribution block individually feeds each component on the industrial panel. Thus, not only does it occupy a significant space on the panel, but it takes a long time to work when considering all measurements, cutting, labeling, pickling and routing the cables. As mentioned before, a copper busbar system replaces the power distribution block and the connection cables which greatly reduces the time it takes to fully integrate the control panel [2]. When there is a power distribution to large components mounted on the industrial panel, as drive systems or power circuit breakers, a busbar 
system can be used in order to replace the large overall sizes parallel cables which connect the main distribution block to devices in adjacent enclosures.

The power distribution systems based on copper busbars offer a number of significant advantages for designers, integrators and industrial control panel users. The busbar systems provide an economical and highly organized power distribution way, which can lead to the decreasing of total costs due to the design and integration of control panels. These systems are widely used around the world and are manufactured in accordance with international standards and norms, which simplifies the implementation process in different international markets.

On the other hand, the busbars allow saving materials thanks that there are necessary fewer connections on current path. The copper of which they are manufactured busbars allow to obtain electrical contacts through simple stamping so, no connection elements are required. This one allows for a time saving during installation.

Connections of the busbars in switchgears are studied from the point of view of the electrical contact resistance and of the temperature (tests and thermal simulations), with some parameters such as: contact pressure, overlap length, and the arrangement of the connections [3]. Measuring the temperature is important because the permanent monitoring can increase the energy transmission efficiency in medium and high voltage and high current switchgear, as described in [4]. Online monitoring of the temperature is important for the reliability and stable operation of the power system [5]. For the buses operating at high voltage it is difficult to measure directly their temperature. For online monitoring, a method to measure temperature of the busbar is presented in [6], with hardware and software description.

In [7] a fault analysis for a substation of $420 \mathrm{kV}$ with double busbar has been considered. It has been paid attention to the protection and how it works. There are quite seldom faults, usually due to failure in the protection system functionality. Temperature measurement on a $10 \mathrm{kV}$ fully insulated busbar is studied in [8], also for the joint conductor, for which the temperature rise is lower because of the heat dissipation. The temperature can be decreased by using slots in the contact area, as presented in [9]. In some special cases the busbar is water-cooled, as for a thermonuclear reactor [10]. The temperature is estimated in busbar, for the cooling water and air, a very important aspect being to calculate the force convection heat transfer inside the busbar cooling water-channel.

The harmonic currents given by the single-phase electronic loads into the network generate heat with negative effects over the busbar system. These currents have to be considered when a busbar is designed and selected, resulting a better solution than a neutral conductor with special design [11]. Current harmonics in busbars and their influence over the busbar are also studied as in [12] considering the currents from a 3-pulse rectifier in order to estimate their effects over the forces which may affect the busbar deformation, supplementary vibrations or insulation break. Current phase comparison is presented [13] as a new method to achieve reliable busbar protection with minimum current transformer performance requirements, with increased the stability of the protection.

Different software can be used for modeling the busbars. In [14] Quich Field software is used for modeling an encapsulated busbar for high voltage, by considering coupling the magnetic field aspects with heat aspects both in stationary and in transient regimes. Opera 2D software can be also used to estimate the distribution of the temperature in three-phase busbar system, as in [15]. PSCAD and MATLAB software are also used for the simulation of different fault situations in busbar protection [16]. Vertical and horizontal arrangement of the busbar is considered in order to study the short-circuit effects [17]. Vertical busbar has over 2 times higher electromagnetic force comparing to the horizontal busbar.

Some protections use busbar protection and advanced zone selection for multiple busbar arrangements with minimum performances requirements for the current transformer [18]. Epoxy coated busbar system is investigated in [19]. For a current of 2000A thermal aspects are studied along the length of the busbar considering the heat distribution by conduction, radiation and convection. For busbars the optimization of the shape and topology are important in order to assure an equal 
power distribution among the components, as presented in [20]. Busbar geometry without supporting epoxy resin insulators are considered in [21] with testing and FEM analysis, for a medium voltage switchgear geometry.

Multi-layer laminated busbar is designed in [22] for power electronic block, with improved interconnection between the capacitor bank and the semiconductor devices and with low-stray inductance, and so with low voltage stress operation. For the laminated busbar topology optimization also enables balancing the materials consumption (especially copper) with the maximum temperature and stray inductance of the busbar [23,24]. Different plating contact surfaces have impact over the temperature distribution at busbar connection, silver plating having the lower contact resistance and lower temperature, as demonstrated in [25]. The temperature variation in the three phase gas insulated switchgear busbar (in the conductor and shield tank) is determined in [26]. A scaling method is used in [27], also for the temperature rise estimation in gas insulated busbar for steady state and transient regime.

Therefore, in the previous works, the authors focused on the current harmonic influences on busbar behaviour, temperature measuring methods (on-line) of busbars, protection and analysis of busbars from power electronics block. Also, it has been presented some thermal simulations of the busbars during fault situations using some common commercial software packages without specifying any mathematical model.

Hence, the purpose of this work is to analyze the temperature distribution along a busbar connection from a power assembly used to supply a test bench for low voltage circuit breakers. The analysis will be performed during steady-state operating conditions. First, it will obtain a mathematical model of the temperature distribution. Then, the theoretical results will be compared with simulated values of a three dimensional thermal model of the same busbar. Finally, some experimental tests will be performed in order to validate the proposed model of the busbar. In fact, the novelty of this work is the mathematical model which includes the temperature variation of the electrical resistivity of the busbar material and the contact resistances at the end terminals of the busbar. This thermal model can be used to investigate simply and quicly the thermal behaviour of the busbar during steady-state conditions.

\section{Mathematical Model}

There are many practical situations when it is necessary to investigate the thermal behaviour of different types of busbars in a simple and fast way without using expensive dedicated software package. More, the nowadays modelling and simulation softwares require a large amount of hard disk space, RAM memory and a very high speed processor. Knowing the thermal load, the geometry and material parameters of the busbar, the proposed mathematical model can be used to calculate the temperature distribution along the busbar during steady-state conditions. The mathematical model takes into consideration the temperature variation of the electric resistivity of the busbar material and also the end terminal contact resistances of the busbar.

The thermal power balance, for one-direction, $x$, Figure 1, of the general differential equation of busbars heating with variable cross-section has the following expression $[2,28]$ :

$$
\rho(\theta) J^{2}(x, t)=\gamma c \frac{\partial \theta(x, t)}{\partial t}-\lambda \frac{\partial^{2} \theta(x, t)}{\partial x^{2}}+\frac{k(\theta) l_{x}}{S_{x}}\left[\theta[x, t]-\theta_{a}\right]
$$

The left term of equation denotes the heating power from the current flow. It is in balance with the heat stored by temporal change of temperature, the power removed from the element by thermal conduction and the thermal flux dissipated through the lateral surface of the conductor. 
In the above heating equation, the temperature variation of electric resistivity is important and could be considered like a parabolic or linear variation. The difference between these two types of variation is small, and because of calculus simplification, the linear form has been chosen:

$$
\rho=\rho_{0}\left(1+\alpha_{0} \theta\right)=\rho_{a}+\alpha_{0} \rho_{0} \vartheta
$$

where,

$$
\vartheta(x)=\theta(x)-\theta_{a}
$$

It knows that the value of global heating transmission coefficient, $\mathrm{k}$, depends on the temperature. In order to obtain a useful temperature rise calculation formula, it supposed an average value for the heating transmission coefficient which not depends on length $\mathrm{x}$ of the busbars.

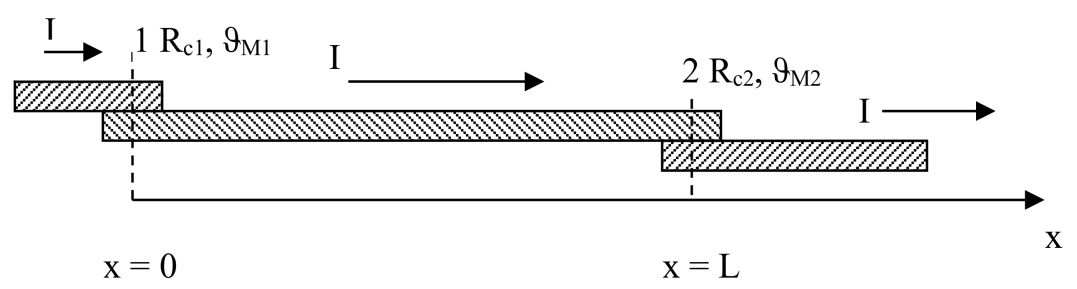

Figure 1. Contact-busbar system: I-current through the contacts and busbar; $x=0$ (point 1 ) and $\mathrm{x}=\mathrm{L}$ (point 2); heat sources due to the contact resistance $\left(\mathrm{R}_{\mathrm{c} 1}\right.$ and $\left.\mathrm{R}_{\mathrm{c} 2}\right)$.

Using the equations (2) and (3) into the thermal power balance expression (1), it gets the following temperature rise equation in the steady-state conditions:

$$
\lambda \frac{d^{2} \vartheta(x)}{d x^{2}}+\left(\alpha_{0} \rho_{0} J^{2}-k \frac{l}{S}\right) \vartheta(x)=-\rho_{a} J^{2}
$$

This is a 2nd order differential equation with constant coefficients and non-zero free term. The general solution of this type of differential equation is:

$$
\vartheta(x)=A_{1} \operatorname{ch}(a x)+A_{2} \operatorname{sh}(a x)+\frac{\rho_{a}}{\lambda a^{2}} J^{2}
$$

where $A_{1}$ and $A_{2}$ mean integration constants which can be established from limit conditions and a, is the root of characteristic differential equation, with the expression:

$$
a=\sqrt{\frac{k l}{\lambda S}-\frac{\rho_{0}}{\lambda} \alpha_{0} J^{2}}
$$

The limit conditions can be written as:

$$
x=0: \quad \frac{P_{1}}{2}=-\lambda S \frac{d \vartheta}{d x} ; \quad x=L: \quad \frac{P_{2}}{2}=-\lambda S \frac{d \vartheta}{d x}
$$

where the contact thermal powers $P_{1}$ and $P_{2}$ are:

$$
P_{1}=R_{c 1} I^{2} ; \quad P_{2}=R_{c 2} I^{2}
$$

Within the contact points 1 and 2, it has been considered for the both electric contacts that a half of the thermal power spreads to the left of the contact point and the other half goes to the right of 
the contact, Figure 1. The assumption is that the busbar is a homogenous type. Thus, results the expressions for the integration constants $A_{1}$ and $A_{2}$,

$$
A_{1}=\frac{I^{2}}{2 \lambda a S}\left[R_{c 1} \operatorname{cth}[a L]-\frac{R_{c 2}}{\operatorname{sh}[a L]}\right] ; \quad A_{2}=-\frac{R_{c 1} I^{2}}{2 \lambda a S}
$$

Thus, after computing the integration constants, $A_{1}$ and $A_{2}$, the equation (5) becomes,

$$
\vartheta(x)=\frac{I^{2} \operatorname{ch}(a x)}{2 \lambda a S}\left[R_{c 1} \operatorname{cth}[a L]-\frac{R_{c 2}}{\operatorname{sh}[a L]}\right]-\frac{R_{c 1} I^{2} \operatorname{sh}(a x)}{2 \lambda a S}+\frac{\rho_{a} I^{2}}{\lambda a^{2} S^{2}}
$$

which means the temperature rise evolution along the busbar length when the values of the contact resistance at the terminals of the busbar are known.

The temperature rise values of the end terminals of the busbar, have the following relations:

$$
x=0: \quad \vartheta(x)=\vartheta_{M 1}=\frac{I^{2}}{2 \lambda a S}\left[R_{c 1} \operatorname{cth}[a L]-\frac{R_{c 2}}{\operatorname{sh}[a L]}\right]+\frac{\rho_{a} I^{2}}{\lambda a^{2} S^{2}}
$$

and,

$$
x=L: \quad \vartheta(x)=\vartheta_{M 2}=\frac{I^{2}}{2 \lambda a S}\left[\frac{R_{c 1}}{\operatorname{sh}[a L]}-R_{c 2} c t h[a L]\right]+\frac{\rho_{a} I^{2}}{\lambda a^{2} S^{2}}
$$

\section{Three-Dimensional Thermal Model}

It has been studied a busbar power assembly which feeds two low voltage power circuit breakers connected in short-circuit. In this way, the power electrical equipment can be tested at high current values. The power supply system has been built as a three-phase high current source. In Figure 2 the main components of the power installation, have been outlined. The main grid feeds a three-phase autotransformer which supplies the high current source. In fact, this current source means a power three-phase transformer which has on the primary side voltage values up to $440 \mathrm{~V}$ and on the secondary side the electric current can reach values up to $12 \mathrm{kA}$. Because of these important output current values, all the electrical connections between the secondary side of the current source and the power circuit breakers, have been done with copper busbars.

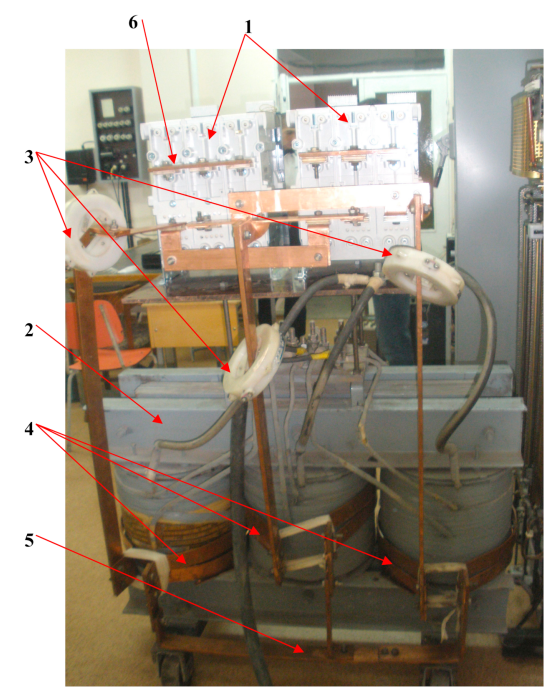

Figure 2. Experimental test bench—rear view (1-circuit breakers in short-circuit connection; 2-high current supply; 3-current transformers; 4-secondaries' turns; 5-busbar for star connection; 6-busbar for short-circuit connection). 
A three-dimensional busbar power assembly which makes the electrical connections between the high current power source and the circuit breakers, has been achieved with the dedicated software package, the Pro-ENGINEER. This software module allow to achieve the 3D geometry of the busbar structure. The three dimensional model of the busbar took into consideration all the components of the power assembly, Figure 3: two turns on each phase of the high current source, busbar links between terminals of the secondary side of the current source to the current path of the circuit breakers, electrical star connection on secondary side and short-circuit busbar on the output terminal of the circuit breaker, [28].

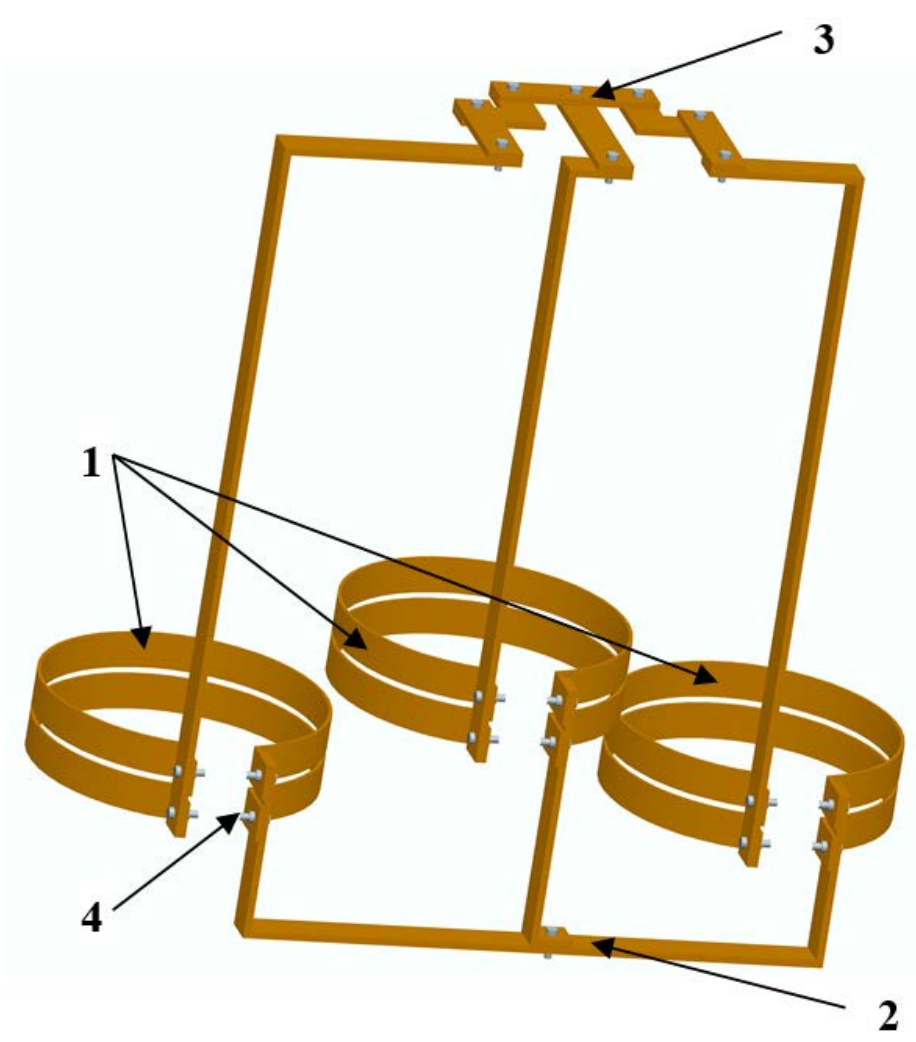

Figure 3. The thermal model of the busbar power assembly (1—turns on secondary side; 2—star busbars connection; 3-short-circuit busbar for circuit breaker; 4-nuts and screws).

Because, the rated current of the tested circuit breakers is $1000 \mathrm{~A}$, it has been assumed the tested current about $1300 \mathrm{~A}$ on each phase. The measurements led to a value of $0.288 \mathrm{~m} \Omega$ for the electric resistance of the busbar power assembly. Therefore, the power losses will be,

$$
P=R \cdot I^{2}=486.72 \mathrm{~W}
$$

The thermal simulations have been performed using the Pro-MECHANICA software module which is based on the finite element method. Actually, this software module gets the 3D geometry from the previous module and it will perform all the necessary thermal simulations. In the Table 1 , there is specified the values of the physical parameters that characterize the busbar power assembly in accordance with Figure 3, [28]. As input for the Pro-MECHANICA module, the thermal load was considered as uniform volume heat source into busbar power assembly.

The mesh of this 3D busbar thermal model has been done using tetrahedron solids element types having the next allowable angle limits (measurement unit: degrees): maximum edge: 175; minimum edge: 5; maximum face: 175; minimum face: 5. The maximum aspect ratio was 30 and the maximum edge turn (measurement unit: degrees): 95. The geometry tolerance had the next values: minimum edge length: 0.0001; minimum surface dimension: 0.0001; minimum cusp angle: 0.86; merge tolerance: 
0.0001. The single pass adaptive convergence method to solve the thermal steady-state simulation has been used.

Table 1. Material data according to Figure 3.

\begin{tabular}{ccc}
\hline \multirow{2}{*}{ Parameter } & \multicolumn{2}{c}{ Material } \\
\cline { 2 - 3 } & Copper (1, 2, 3) & Iron FE40 (4) \\
\hline$\gamma\left[\mathrm{kg} / \mathrm{m}^{3}\right]$ & 8900 & 7190 \\
$\mathrm{c}\left[\mathrm{J} / \mathrm{kg}^{\circ} \mathrm{C}\right]$ & 387 & 420.27 \\
$\lambda\left[\mathrm{W} / \mathrm{m}^{\circ} \mathrm{C}\right]$ & 385 & 52.028 \\
\hline
\end{tabular}

After some experimental tests, it has been calculated the convection coefficient with a value of $14.3 \mathrm{~W} / \mathrm{m}^{2}{ }^{\circ} \mathrm{C}$. As boundary condition it has been considered the thermal convection from the busbar assembly to the environement. As input for the Pro-MECHANICA module, the convection value was applied on the outer surfaces of the busbar components. It has been considered a uniform spatial variation. The bulk temperature was about $25^{\circ} \mathrm{C}$. The busbars are made from copper with the cross-section of $50 \mathrm{~mm} \times 10 \mathrm{~mm}$.

Forwards, some thermal simulations have been performed during steady-state conditions. The thermal spectrum of the busbar power assembly is presented in Figure 4, as a result of Pro-MECHANICA software simulations. The maximum temperature rise value, $63.3^{\circ} \mathrm{C}$ is observed on the busbars which make the star connection, and the minimum temperature rise value of $27.6{ }^{\circ} \mathrm{C}$ is noted on the upper busbars. The output terminals of the power circuit breaker have been short-circuited. These values are due to the proximity of the star connection busbars with the thermal source from the secondaries of the high current supply. So, its temperature rise is higher than the upper busbar connection that makes the short-circuit condition for the tested power circuit breaker. On the other hand, the length of the busbar connection from the secondary terminal to the upper short-circuit busbar, has an important value. So, the external busbar surfaces lead to lower temperatures because of convection and radiation thermal transfer to the environment. For the middle busbar, there is a temperature rise variation from $\vartheta_{\mathrm{M} 1}=51.2{ }^{\circ} \mathrm{C}$, on the connection with the two turns on the secondary of high current supply, to $\vartheta_{\mathrm{M} 2}=30.3^{\circ} \mathrm{C}$ on the terminal of the upper side of the busbar.

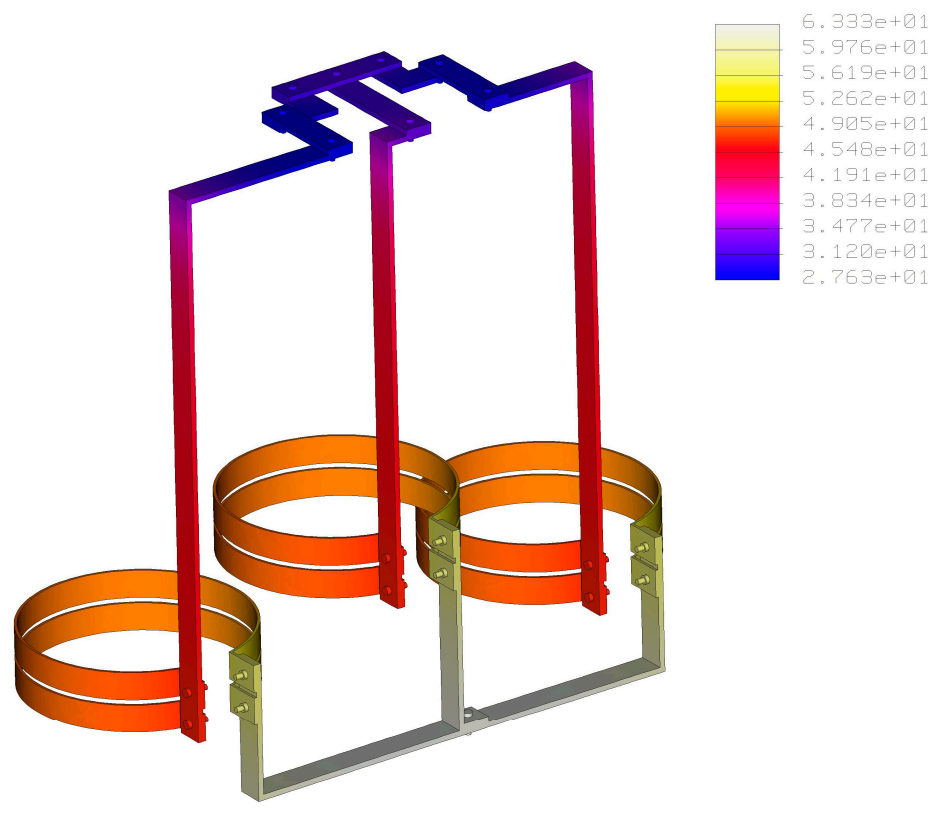

Figure 4. Temperature spectrum of the busbar power assembly in the case of test current I = $1300 \mathrm{~A}$. 


\section{Discussion of the Results}

Considering the solution for the equation of temperature rise (10), it can be analyzed the influence of electrical and geometrical parameters on the busbar heating. Further on, the thermal analysis refers to the middle busbar of the high current power supply assembly, which makes the connection between the two turnes of the secondary side and the middle upper terminal of short-circuit connection in order to test power circuit breakers. The busbar is made from copper with the following physical parameters: $\rho_{\mathrm{a}}=1.72 \times 10^{-8} \Omega \mathrm{m}, \lambda=385 \mathrm{~W} / \mathrm{m}^{\circ} \mathrm{C}, \alpha_{0}=4 \times 10^{-3} 1 /{ }^{\circ} \mathrm{C}$. It has been measured the following contact resistances: $R_{c 1}=10 \mu \Omega$, on the junction with secondary turns, and $R_{c 2}=5 \mu \Omega$, on the upper terminal of the busbar.

The first analysis took into consideration the variation of the electric current through the busbar, from 800 to 1600 A, Figure 5.

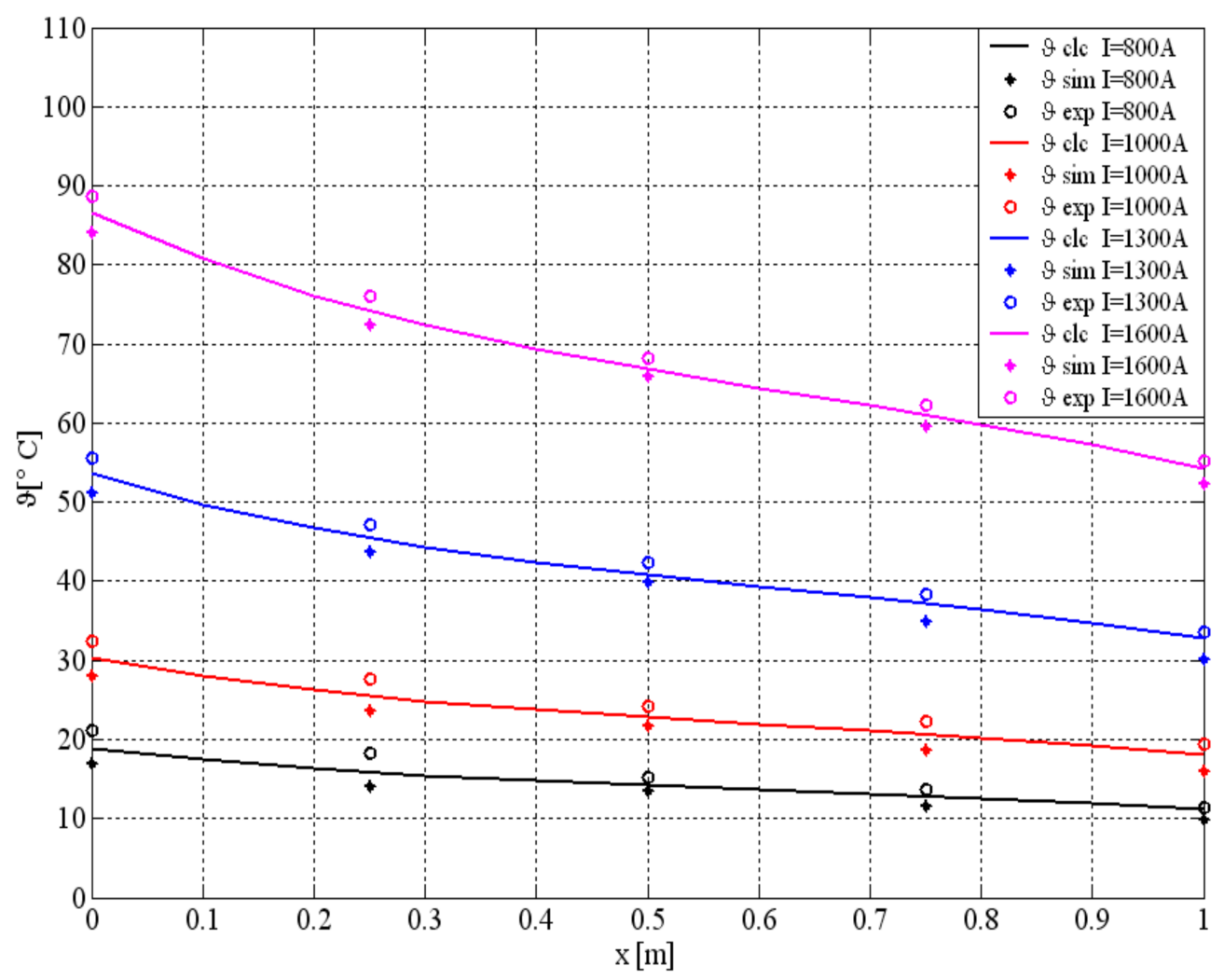

Figure 5. Temperature rise variation against busbar length for different current values. Comparison between calculated values $\vartheta_{\text {clc }}$, simulated values $\vartheta_{\text {sim }}$ and experimental values $\vartheta_{\text {exp }}$.

As expected, the temperature of the conductor increases as the current increases. For $800 \mathrm{~A}$, the difference between the terminals of the busbar $(x=0 \mathrm{~m}$ and $\mathrm{x}=1 \mathrm{~m})$ is about $7.7^{\circ} \mathrm{C} .\left(\vartheta_{\mathrm{M} 1}=18.9^{\circ} \mathrm{C}\right.$ and $\left.\vartheta_{\mathrm{M} 2}=11.2^{\circ} \mathrm{C}\right)$. When the electric current has the value of $1600 \mathrm{~A}$, the difference between the terminals' temperature rise is increased at $32.4^{\circ} \mathrm{C}\left(\vartheta_{\mathrm{M} 1}=86.6^{\circ} \mathrm{C}\right.$ and $\left.\vartheta_{\mathrm{M} 2}=54.2{ }^{\circ} \mathrm{C}\right)$. This is because the temperature rise and the temperature along the busbar are directly proportional with the square current through the conductor. It can be observed that the simulation values are lower than the calculated ones, especially at the terminals of the busbar. For instance, at $800 \mathrm{~A}$, the temperature rise values at terminals are $\vartheta_{\mathrm{M} 1}=16.9^{\circ} \mathrm{C}$ and $\vartheta_{\mathrm{M} 2}=9.8^{\circ} \mathrm{C}$, respect to $\vartheta_{\mathrm{M} 1}=18.9^{\circ} \mathrm{C}$ and $\vartheta_{\mathrm{M} 2}=11.2^{\circ} \mathrm{C}$, the calculated values. Also, in the case of $1600 \mathrm{~A}$, the simulated values of busbar terminals are $\vartheta_{\mathrm{M} 1}=84.1^{\circ} \mathrm{C}$ and $\vartheta_{\mathrm{M} 2}=52.4^{\circ} \mathrm{C}$, respect to $\vartheta_{\mathrm{M} 1}=86.6^{\circ} \mathrm{C}$ and $\vartheta_{\mathrm{M} 2}=54.2^{\circ} \mathrm{C}$, the calculated values. This is explained because the terminals of the busbar are connected with other busbar conductors, therefore, in the contact points ( 1 and 2 ) the link conductors act as a real hetasink for the main busbar. 
The second thermal analysis has been performed for the variation of the cross-section of the busbar. The next values of the cross-section: $300 \mathrm{~mm}^{2}, 500 \mathrm{~mm}^{2}, 700 \mathrm{~mm}^{2}$ and $900 \mathrm{~mm}^{2}$, have been considered. As the cross-section increases, the temperature rise decreases, Figure 6.

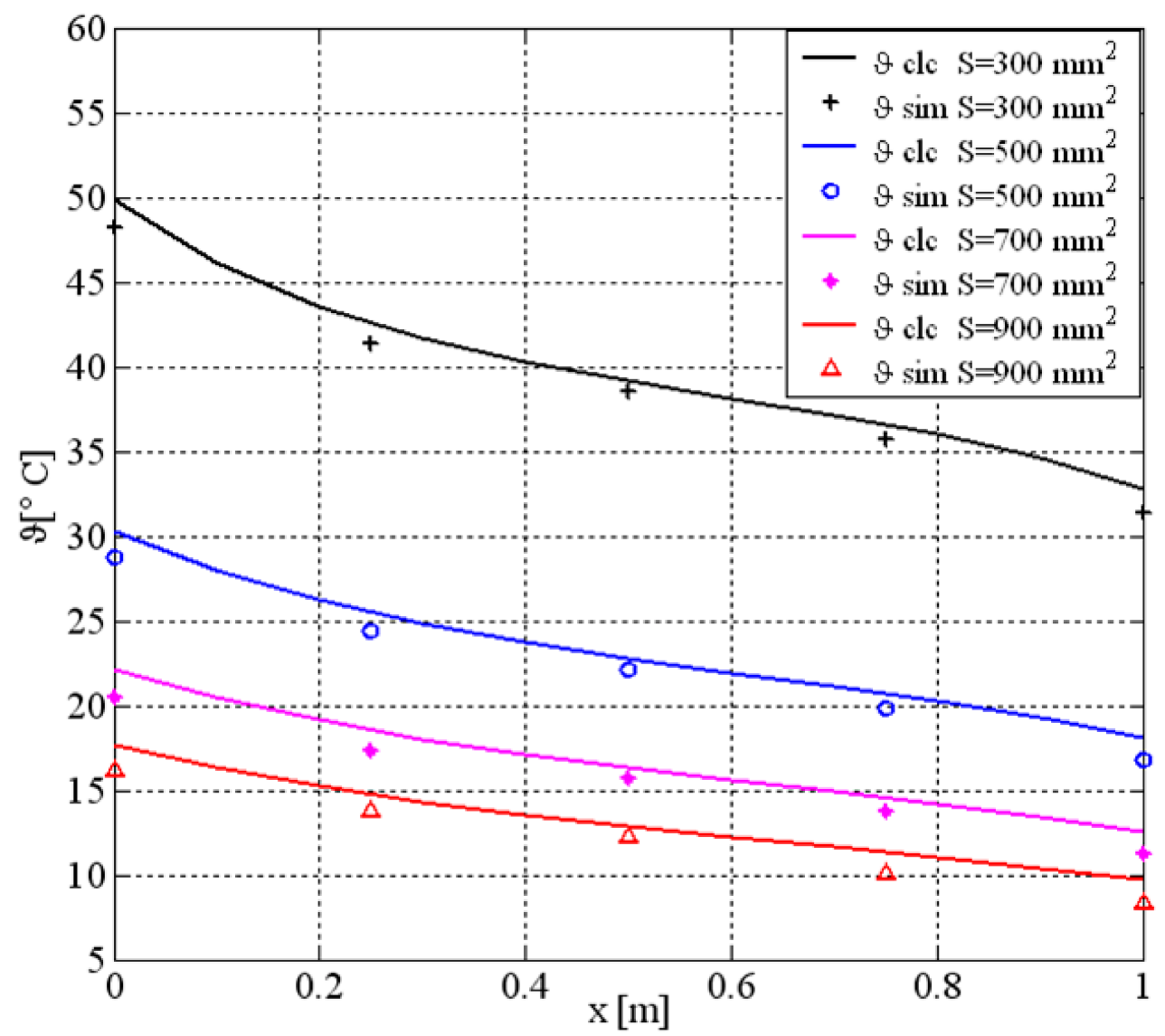

Figure 6. Temperature rise variation against busbar length for different cross-section busbar values. Comparison between calculated values $\vartheta_{\mathrm{clc}}$ and simulated values $\vartheta_{\text {sim }}$.

The explanation of this observation is that the temperature rise is inverse proportional to the cross-section of the busbar. For instance, at the cross-section value of $300 \mathrm{~mm}^{2}$, the terminal values of the temperature rise are $\vartheta_{\mathrm{M} 1}=49.8^{\circ} \mathrm{C}(\mathrm{x}=0)$ and $\vartheta_{\mathrm{M} 2}=32.7^{\circ} \mathrm{C}(\mathrm{x}=1 \mathrm{~m})$. In the case of the cross-section value of $900 \mathrm{~mm}^{2}$, the difference between the terminal values of the temperature rise is only about $7.9^{\circ} \mathrm{C}\left(\vartheta_{\mathrm{M} 1}=17.6^{\circ} \mathrm{C}\right.$ and $\left.\vartheta_{\mathrm{M} 2}=9.7^{\circ} \mathrm{C}\right)$. As in previous analyzed case, the simulation values are lower than the calculated ones. So, when the cross-section of the busbar has the value of $300 \mathrm{~mm}^{2}$, the temperature rise at the terminals'busbar are $\vartheta_{\mathrm{M} 1}=48.2^{\circ} \mathrm{C}$ and $\vartheta_{\mathrm{M} 2}=31.4{ }^{\circ} \mathrm{C}$, and if the cross-section of the busbar is about $900 \mathrm{~mm}^{2}$, than the temperature rise values at terminals are $\vartheta_{\mathrm{M} 1}=16.1^{\circ} \mathrm{C}$ and $\vartheta_{\mathrm{M} 2}=8.3^{\circ} \mathrm{C}$.

The next thermal analysis has been carried out for the variation of length of the busbar. When the busbar length increases from 0.6 to $1.4 \mathrm{~m}$, the temperature rise of the lower terminal $(\mathrm{x}=0)$ has no significantly increasing, from $\vartheta_{\mathrm{M} 1}=17.3^{\circ} \mathrm{C}$ at busbar length of $0.6 \mathrm{~m}$ to $\vartheta_{\mathrm{M} 1}=17.9^{\circ} \mathrm{C}$ when the busbar length is about $1.4 \mathrm{~m}$, as it can be seen from the graphics shown in Figure 7. On the other hand, the temperature rise of the upper terminal $(x=\mathrm{L})$ has a small decreasing, from $\vartheta_{\mathrm{M} 2}=11.6^{\circ} \mathrm{C}$ at busbar length of $0.6 \mathrm{~m}$ to $\vartheta_{\mathrm{M} 2}=8.9^{\circ} \mathrm{C}$ when the busbar length is $1.4 \mathrm{~m}$. Similar to previous cases, the simulation results are lower than the computed ones. Thus, when the length of the busbar has the value of $0.6 \mathrm{~m}$, the temperature rise at the terminals'busbar are $\vartheta_{\mathrm{M} 1}=15.8^{\circ} \mathrm{C}$ and $\vartheta_{\mathrm{M} 2}=10.2{ }^{\circ} \mathrm{C}$, and for the busbur length of $1.4 \mathrm{~m}$, the temperature rise values at terminals are $\vartheta_{\mathrm{M} 1}=16.5^{\circ} \mathrm{C}$ and $\vartheta_{\mathrm{M} 2}=7.4^{\circ} \mathrm{C}$. 


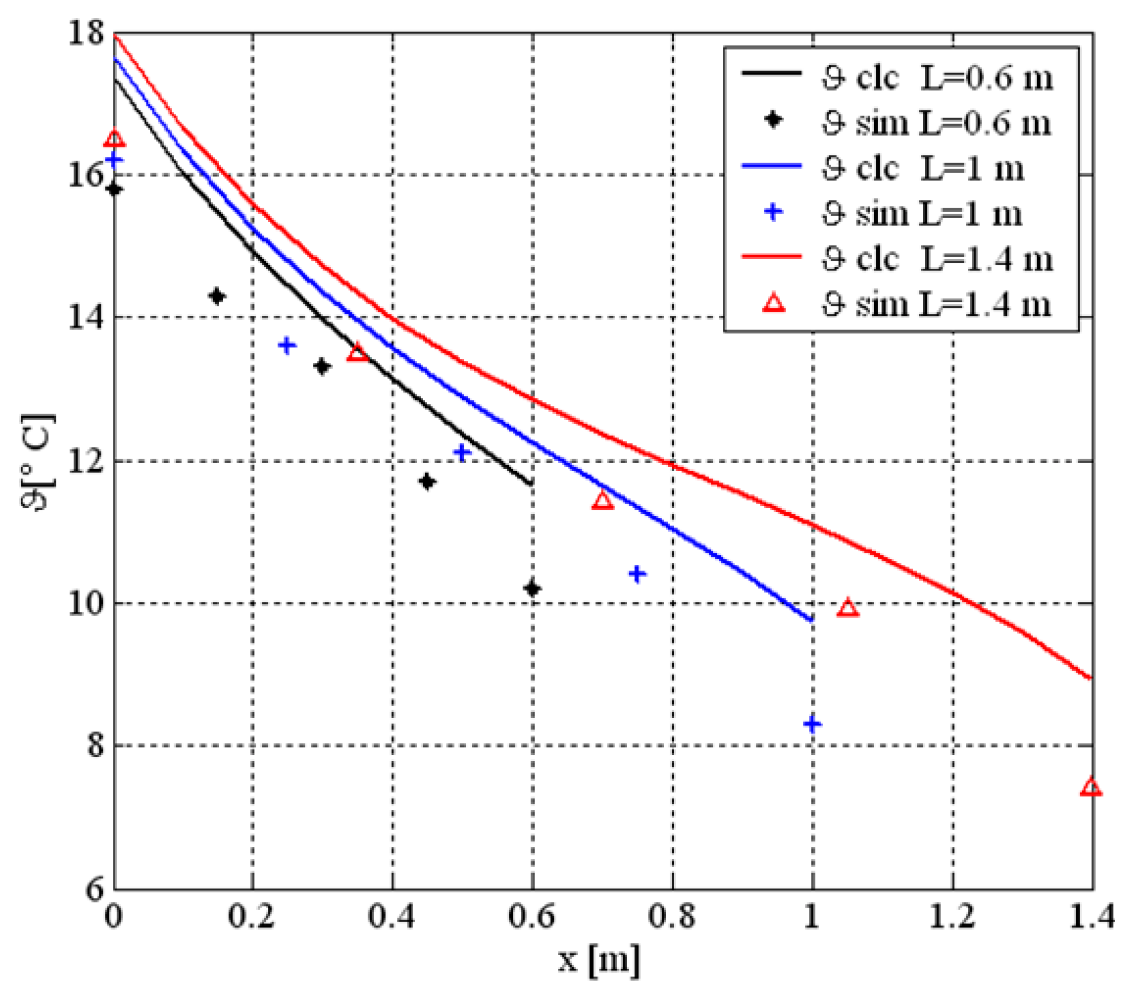

Figure 7. Temperature rise variation for different busbar length values. Comparison between calculated values $\vartheta_{\text {clc }}$ and simulated values $\vartheta_{\text {sim }}$.

An important parameter that influences the temperature distribution along the busbar is the contact resistance. Its value depends on the contact force with which the bolts between the busbar terminals have been fastened. In the Figure 8 is shown the variation of the temperature rise against busbar length at different contact resistance values, from $7 \mu \Omega$ to $20 \mu \Omega$.

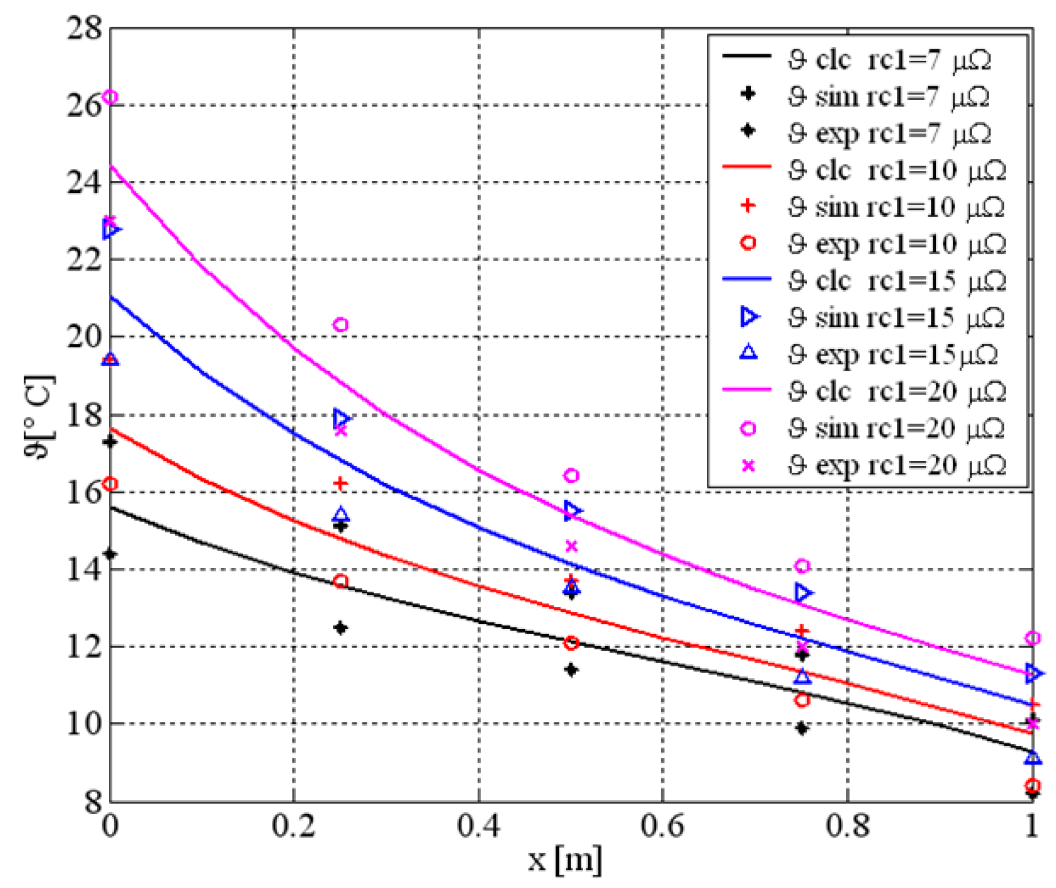

Figure 8. Temperature rise variation against busbar length for different contact resistance values. Comparison between calculated values $\vartheta_{\text {clc }}$, simulated values $\vartheta_{\text {sim }}$ and experimental values $\vartheta_{\text {exp }}$. 
It can be noticed an increasing of the temperature rise values when the contact resistance is also increasing. This is because the temperature rise depends on the power loss which is directly proportional with the contact resistance value. Thus, there is a variation of the terminals temperature rise values from $\vartheta_{\mathrm{M} 1}=15.6^{\circ} \mathrm{C}$ to $\vartheta_{\mathrm{M} 2}=9.2^{\circ} \mathrm{C}$ when the contact resistance is $7 \mu \Omega$ and from $\vartheta_{\mathrm{M} 1}=24.4^{\circ} \mathrm{C}$ to $\vartheta_{\mathrm{M} 2}=11.2^{\circ} \mathrm{C}$ when the contact resistance has the value of $20 \mu \Omega$. As in previous thermal analysis, the simulation values are lower than the calculated results. Therefore, when the contact resistance has the value of $7 \mu \Omega$, the temperature rise at the terminals'busbar are $\vartheta_{\mathrm{M} 1}=14.4{ }^{\circ} \mathrm{C}$ and $\vartheta_{\mathrm{M} 2}=8.2{ }^{\circ} \mathrm{C}$, and for the contact resistance of $20 \mu \Omega$, the temperature rise values at terminals are $\vartheta_{\mathrm{M} 1}=23^{\circ} \mathrm{C}$ and $\vartheta_{\mathrm{M} 2}=10^{\circ} \mathrm{C}$.

To validate the proposed mathematical model and the simulation results, some experimental tests have been performed. The temperature acquisition system is made with a microcontroller type PIC 16F871P. The temperature data is obtained from an infrared transducer which converts the temperature information into a dc voltage signal. The clock frequency is provided by an auxiliary quartz of $20 \mathrm{MHz}$. The acquisition system is supplied with $5 \mathrm{Vdc}$ through a transformer and a stabilized electronic circuit type LM7805.

The microcontroller type PIC 16F871P has been programmed to acquire the analogue voltage signal from the infrared transducer and to convert it into a digital signal. Then, the digital signal is processed by a LabVIEW application. The experimental set-up is presented in Figure 9.

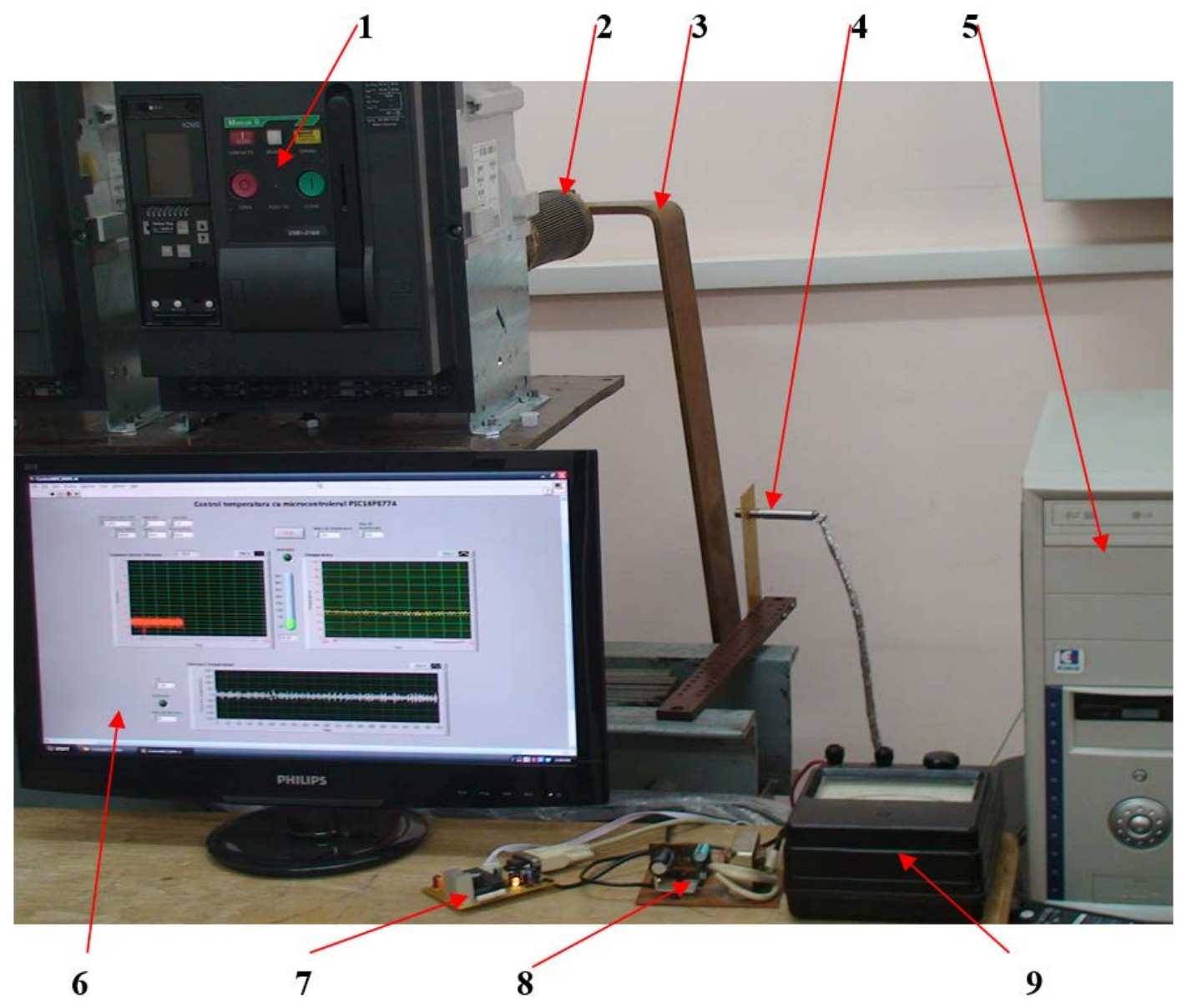

Figure 9. Experimental se tup for temperature acquisition system (1-power circuit breaker; 2-coaxial current shunt; 3-busbar; 4-infrared transducer; 5-PC; 6-LabVIEW application; 7—electronic circuit board; 8-power supply for electronic circuit; 9-ammeter).

Because of technological reasons, the experimental tests have been performed only in the case of variation of the electric current and contact resistance. In the case of current variation, Figure 5, 
at $1600 \mathrm{~A}$, the experimental values of busbar terminals are $\vartheta_{\mathrm{M} 1}=88.7^{\circ} \mathrm{C}$ and $\vartheta_{\mathrm{M} 2}=55.1^{\circ} \mathrm{C}$, respect to $\vartheta_{\mathrm{M} 1}=86.6^{\circ} \mathrm{C}$ and $\vartheta_{\mathrm{M} 2}=54.2^{\circ} \mathrm{C}$, the calculated values. It can be observed higher experimental values respect to calculated ones. The same observation is valid in the case of contact resisatnce variation, Figure 8: when the contact resisatnce has the value of $7 \mu \Omega$, the temperature rise at the terminals'busbar are $\vartheta_{\mathrm{M} 1}=17.3^{\circ} \mathrm{C}$ and $\vartheta_{\mathrm{M} 2}=10.1^{\circ} \mathrm{C}$ respect to $\vartheta_{\mathrm{M} 1}=15.6^{\circ} \mathrm{C}$ and $\vartheta_{\mathrm{M} 2}=9.2^{\circ} \mathrm{C}$, the calculated ones, and for the contact resistance of $20 \mu \Omega$, the temperature rise values at terminals are $\vartheta_{\mathrm{M} 1}=26.2^{\circ} \mathrm{C}$ and $\vartheta_{\mathrm{M} 2}=12.2^{\circ} \mathrm{C}$ respect to $\vartheta_{\mathrm{M} 1}=24.4{ }^{\circ} \mathrm{C}$ to $\vartheta_{\mathrm{M} 2}=11.2^{\circ} \mathrm{C}$, the calculated ones.

It can be observed that there are differencies between experimental tests values and calculations from mathematical model. This is due to mathematical model assumptions, thermal simulations errors, measurement accuracy, manufacturing of the experimental test-bench, etc. It can be noticed that the difference between calculation results and experimental values is under $2{ }^{\circ} \mathrm{C}$.

\section{Conclusions}

In this paper, a mathematical model related to the temperature rise distribution of a busbar from a high current power supply, is described. The thermal model allows for computation of the temperature rise in the case of electric current variation, cross-section and length variation of the busbar, and in the case of contact resistance variation. Using the 3D thermal modelling and simulation, there is possibility to improve the busbar designing and to obtain new solutions for a better correlation between time-current characteristics of circuit breakers and busbar design.

The proposed mathematical model has been validated through experimental tests. There is a good correlation between experimental, simulation and computing of temperature rise values.

The thermal model can be used as an useful tool to design different type of busbars with an appropriate temperature distribution depending on different electrical, geometrical and mechanical parameters. Using a simple mathematical equation, there is the possibility to save the money of the expensive dedicated software packages and hardware facilites of the PC with the aim to obtain the thermal simulation results.

Author Contributions: The whole article has been performed only by the author.

Acknowledgments: The author had not received any funds for covering the costs to publish in open access.

Conflicts of Interest: The author declares no conflict of interest.

\section{Nomenclature}

$\theta \quad$ means the temperature of busbar $\left[{ }^{\circ} \mathrm{C}\right]$

$\theta_{\mathrm{a}} \quad$ ambient temperature $\left[{ }^{\circ} \mathrm{C}\right]$

j current density $\left[\mathrm{A} / \mathrm{m}^{2}\right]$;

$\rho_{0} \quad$ electrical rezistivity at $0^{\circ} \mathrm{C}[\Omega \mathrm{m}]$;

$\rho_{\mathrm{a}} \quad$ electrical rezistivity at ambient temperature $\left(20^{\circ} \mathrm{C}\right)[\Omega \mathrm{m}]$;

$\gamma \quad$ material density $\left[\mathrm{kg} / \mathrm{m}^{3}\right]$;

c specific heat $\left[\mathrm{J} / \mathrm{kg}^{\circ} \mathrm{C}\right]$;

$\lambda \quad$ thermal conductivity $\left[\mathrm{W} / \mathrm{m}^{\circ} \mathrm{C}\right]$;

$\alpha_{0} \quad$ temperature variation coefficient of the electrical resistivity $\left[1 /{ }^{\circ} \mathrm{C}\right]$;

$\mathrm{k} \quad$ convection coefficient $\left[\mathrm{W} / \mathrm{m}^{2 \circ} \mathrm{C}\right]$;

$\mathrm{L} \quad$ length of the busbar [m];

1 perimeter of the cross-section of the busbar [m];

$\mathrm{S} \quad$ cross-section of the busbar $\left[\mathrm{m}^{2}\right]$;

$\mathrm{P}_{1}, \mathrm{P}_{2} \quad$ power losses [W];

$\mathrm{R}_{\mathrm{c} 1}, \mathrm{R}_{\mathrm{c} 2} \quad$ contact resistances $[\Omega]$;

I current through the busbar [A];

$\mathrm{R} \quad$ electric resistance of the busbar $[\Omega]$. 


\section{References}

1. Chapman, D.; Norris, T. Copper for Busbars_Guidance for Design and Installation; Publication No. Cu0201; European Copper Institute: Hemel Hempstead, UK, 2014.

2. Plesca, A. Protection of Low Voltage Electrical Installations; Tehnopress Publishing House: Iasi, Romania, 2015.

3. Park, S.W.; Cho, H. A practical study on electrical contact resistance and temperature rise at at the connections of the copper busbars in switchgears. In Proceedings of the 2014 IEEE 60th Holm Conference on Electrical Contacts (Holm), New Orleans, LA, USA, 12-15 October 2014; pp. 1-7. [CrossRef]

4. Sabah, S.; Buehler, T.; Buchter, F. Temperature monitoring of switchgear utilizing Surface Acoustic Wave wireless sensors. In Proceedings of the 2011 IEEE/PES Power Systems Conference and Exposition, Phoenix, AZ, USA, 20-23 March 2011; p. 1. [CrossRef]

5. Li, X.; Gao, N.; Wu, W. A modified self-powered wireless temperature measurement system for high voltage switchgear. In Proceedings of the 2018 13th IEEE Conference on Industrial Electronics and Applications (ICIEA), Wuhan, China, 31 May-2 June 2018; pp. 1425-1430. [CrossRef]

6. Linsuo, Z.; Maojun, W. The Design and Realization of on-line Measuring Device of Busbar Temperature Rise for HV Switch Board. In Proceedings of the 2006 International Conference on Power System Technology, Chongqing, China, 22-26 October 2006; pp. 1-5. [CrossRef]

7. Loken, R.S.J.; Bostad, A.; Ingebrigtsen, S. Utility experiences on busbar faults in a transmission grid. In Proceedings of the 12th IET International Conference on Developments in Power System Protection (DPSP 2014), Copenhagen, Denmark, 31 March-3 April 2014; pp. 1-5. [CrossRef]

8. Zhang, Z.; Rao, W.; Ruan, L.; Zhao, J.-k.; Meng, S.-x.; Yang, F. Research on the temperature rise characteristic of $10 \mathrm{kV}$ fully insulated busbar system. In Proceedings of the 2016 China International Conference on Electricity Distribution (CICED), Xi'an, China, 10-13 August 2016; pp. 1-4. [CrossRef]

9. Lotiya, J. Thermal analysis and optimization of temperature rise in busbar joints configuration by FEM. In Proceedings of the 2014 6th IEEE Power India International Conference (PIICON), Delhi, India, 5-7 December 2014; pp. 1-5. [CrossRef]

10. Guo, B.; Song, Z.; Fu, P.; Jiang, L.; Wang, M.; Dong, L. Prediction of Temperature Rise in Water-Cooling DC Busbar Through Coupled Force and Natural Convection Thermal-Fluid Analysis. IEEE Trans. Plasma Sci. 2016, 44, 3346-3352. [CrossRef]

11. Lepretre, P.; Mary, M.; Schonek, J. Taking account of harmonic currents in the selection of-busbar systems. In Proceedings of the 2004 11th International Conference on Harmonics and Quality of Power (IEEE Cat. No. 04EX951), Lake Placid, NY, USA, 12-15 September 2004; pp. 41-45. [CrossRef]

12. Abd-El-Aziz, M.M.; Nashed, M.N.; Adly, A.A.; Essam-El-Din, M. Computation of busbars local electromagnetic force densities connected to 3-pulse rectifier load over a complete cycle. In Proceedings of the 2008 12th International Middle-East Power System Conference, Aswan, Egypt, 12-15 March 2008; pp. 550-554. [CrossRef]

13. Xu, L.; Grasset, H.; Dong, X.; Xu, C.; Xu, R. A new method for busbar protection stability improvement. In Proceedings of the 10th IET International Conference on Developments in Power System Protection (DPSP 2010), Manchester, UK, 29 March-1 April 2010; pp. 1-4. [CrossRef]

14. Popa, I.C.; Dolan, A.I.; Ghindeanu, D.; Boltaşu, C. Thermal modeling and experimental validation of an encapsulated busbars system. In Proceedings of the 2014 18th International Symposium on Electrical Apparatus and Technologies (SIELA), Bourgas, Bulgaria, 29-31 May 2014; pp. 1-4. [CrossRef]

15. Muhammood, M.; Kamarol, M.; Ishak, D.; Masri, S. Temperature rise prediction in 3-phase busbar system at $20{ }^{\circ} \mathrm{C}$ ambient temperature. In Proceedings of the 2012 IEEE International Conference on Power and Energy (PECon), Kota Kinabalu, Malaysia, 2-5 December 2012; pp. 736-740. [CrossRef]

16. Xu, X.; Li, H.; Wen, H. Performance evaluation of busbar protection schemes under different fault scenarios. In Proceedings of the 2015 9th International Conference on Power Electronics and ECCE Asia (ICPE-ECCE Asia), Seoul, Korea, 1-5 June 2015; pp. 1597-1602. [CrossRef]

17. Yusop, F.M.; Jamil, M.K.M.; Ishak, D.; Masri, S. Study on the electromagnetic force affected by short-circuit current in vertical and horizontal arrangement of busbar system. In Proceedings of the International Conference on Electrical, Control and Computer Engineering 2011 (InECCE), Pahang, Malaysia, 21-22 June 2011; pp. 196-200. [CrossRef] 
18. Guzmán, A.; Qin, B.L.; Labuschagne, C. Reliable busbar protection with advanced zone selection. IEEE Trans. Power Deliv. 2005, 20, 625-629. [CrossRef]

19. Viswanatha, C.; Rakesh, K.G. Investigation of epoxy coated Busbar system enclosed in LT busduct of rating 2000A. In Proceedings of the 2016 IEEE 6th International Conference on Power Systems (ICPS), New Delhi, India, 4-6 March 2016; pp. 1-5. [CrossRef]

20. Petrášová, I.; Karban, P.; Pánek, D.; Šroubová, L. Shape and Topology Optimization of High Power Converter Busbar. In Proceedings of the 19th International Conference Computational Problems of Electrical Engineering, Banska Stiavnica, Slovakia, 9-12 September 2018; pp. 1-4. [CrossRef]

21. Zubčić, M.; Krčum, M. Power frequency withstand voltage type testing and FEM analysis of the medium-voltage switchgear busbar compartment. In Proceedings of the 2018 17th International Symposium INFOTEH-JAHORINA (INFOTEH), East Sarajevo, Republic of Srpska, 21-23 March 2018; pp. 1-5. [CrossRef]

22. Deshpande, A.; Luo, F. Multilayer busbar design for a Si IGBT and SiC MOSFET hybrid switch based $100 \mathrm{~kW}$ three-level T-type PEBB. In Proceedings of the 2017 IEEE 5th Workshop on Wide Bandgap Power Devices and Applications (WiPDA), Albuquerque, NM, USA, 30 October-1 November 2017; pp. 20-24. [CrossRef]

23. Puigdellivol, O.; Le Menach, Y.; Harmand, S.; Méresse, D.; Wecxsteen, J.F. Multiphysics topology optimization for laminated busbars. In Proceedings of the 2016 IEEE Conference on Electromagnetic Field Computation (CEFC), Miami, FL, USA, 13-16 November 2016; p. 1. [CrossRef]

24. Smirnova, L.; Juntunen, R.; Murashko, K.; Musikka, T.; Pyrhönen, J. Thermal analysis of the laminated busbar system of a multilevel converter. IEEE Trans. Power Electron. 2016, 31, 1479-1488. [CrossRef]

25. Risdiyanto, A.; Arifin, M.; Khayam, U. Study on temperature distribution at busbar connection based on contact resistance of different plating contact surface. In Proceedings of the 2013 Joint International Conference on Rural Information Communication Technology and Electric-Vehicle Technology (rICT \& ICeV-T), Bandung, Indonesia, 26-28 November 2013; pp. 1-6. [CrossRef]

26. Kim, H.K.; Oh, Y.H.; Lee, S.H. Prediction of temperature rise in gas insulated busbar using multi-physics analysis. In Proceedings of the 2009 Transmission Distribution Conference Exposition: Asia and Pacific, Seoul, Korea, 26-30 October 2009; pp. 1-4. [CrossRef]

27. Li, H.; Shu, N.; Wu, X. Study on Temperature Rise Scaling Relationships of Gas Insulated Busbar. In Proceedings of the 2012 Sixth International Conference on Electromagnetic Field Problems and Applications, Dalian, China, 19-21 June 2012; pp. 1-4. [CrossRef]

28. Plesca, A.; Scintee, A. 3D thermal analysis of a power supply busbar structure. In Proceedings of the 2010 ASME 10th Biennial Conference on Engineering Systems Design and Analysis, Istanbul, Turkey, 12-14 July 2010; pp. 695-702. [CrossRef] 